\title{
TO STUDY THE PREVALENCE OF NUTRITIONAL ANAEMIA IN FEMALE STUDENTS OF DR DY PATIL HIMCRC OF AGE GROUP 18-22 YEARS AGE, PUNE
}

KEY WORDS: Nutrition Anaemia, adolescent girls.

\section{Dr. Sonali Dalvi*}

Professor, Department of Gynaecology and Obstetrics, Dr. D. Y. Patil Homoeopathic Medical College and Research Centre, Dr. D. Y. Patil Vidyapeeth, Pimpri, Pune, Maharashtra, India. *Corresponding Author

Assistant Professor, Department of Community Medicine, Dr. D. Y. Patil Vidyapeeth,Pimpri, Pune, Maharashtra, India.

Anaemia is one of the commonest hematological disorders and continues to be a major health problem in India. Iron deficiency anaemia is a serious public health concern. It is an important medical condition considering the health of women. Most of the anaemias are nutritional, predominantly due to iron deficiency. The main objective of the study was to assess the prevalence, awareness and knowledge of anaemia among adolescence and adult females. Total 76 female participants of age 18-22 yrs were included in the study through random sampling method. Out of which, 43 were anemic, where $53.48 \%$ were on pure vegetarian diet, $39.53 \%$ had mixed diet and only $6.97 \%$ had non vegetarian diet. In 33 non anaemic participants $54.54 \%$ had mixed diet, $33.33 \%$ had vegetarian and $12.12 \%$ had non vegetarian diet. Anaemia continues to be a common health problem among adolescence girls and reproductive age women. Excessive blood loss during menses / menorrhagia, traditional eating habits, fear of gaining weight and examination anxiety and irregular eating habits are major causes for anaemia.

Early detection of anaemia is important, so that mild and moderate grade can be promptly treated and prevented from developing severe anaemia which can adversely affect health. Prevention of anaemia can be effective when the strategy on appropriate treatment is focused right from the adolescence for their future reproductive life.

\section{INTRODUCTION}

Anaemia affects a large section of the global population of all ages. It is a public health problem affecting both developing and developed countries with major consequences for human health as well as social and economic development ${ }^{[1]}$. There is increase in the nutritional requirements of adolescent girls after the onset of puberty. It is the period of life when maximum amount of physical, psychological and behavioral changes take place. Adolescent girls and young women, who constitute a major segment of the population, are at a greater risk of developing adverse effects of anaemia.

Anaemia has got adverse effects on cognitive and motor development. It causes fatigue and low productivity, and when it occurs in pregnancy, it is associated with low birth weight and increased risk of maternal and prenatal mortality. So prevention of anemia has to be focused right from the adolescence age group for their future reproductive life.

\section{AIM AND OBJECTIVES}

- To assess the prevalence of anaemia among adolescence and young adults.

- To assess the awareness and knowledge about anaemia among adolescent girls and young adults.

\section{PURPOSE OF SELECTION OFTOPIC:}

Iron deficiency anaemia is more common in women due to excessive loss of iron or demand of iron associated with menstruation and child birth.

Complications of anemia include preeclampsia, inter-current infections, heart failure, preterm labor, uterine inertia, PPH, cardiac failure, shock during labor and increased chances of puerperal sepsis, sub-involution, poor lactation in puerperium. $^{[2]}$

The iron requirement is more and inadequate dietary intake, faulty dietary habits in adolescent girls and in these young women of reproductive age and low iron storage during this period will make them susceptible during pregnancy, because dietary intake alone is insufficient in most cases to meet the requirement of pregnancy. Thus adolescence is second high risk period for anaemia. ${ }^{[3]}$
Lack of dietary knowledge and food fads like skipping meals at home, irregular eating habits, eating junk food (less in nutritious content) crash diets, etc can lead to nutritional anaemia in adolescents. ${ }^{[4]}$

\section{MATERIALS AND METHODS}

- Research Design: Observational survey approach was used in the study to assess the prevalence, awareness and knowledge of anemia in female participants between the age group 18-23 yrs.

- Selection of Study Group: Total 76 female participants of age 18-22 years were included in the study through random sampling method.

- Inclusion Criteria: Female participants who have submitted the consent form duly signed and who are willing to participate in the study were included with the age group of 18-22 years.

- Exclusion Criteria: Those participants who had blood transfusion or who were on haematinics in past 4 weeks were excluded.

- Study Design: A cross sectional study was executed among 76 female subjects. (Observational study)

- Duration:The duration required was period of one year.

- Selection of Tools:

- Standard case taking performa was used.

- The medical history, menstrual history and the diet pattern was collected from the students diagnosed anaemic during the investigation.

- Laboratory investigation - Haemogram of each participant was conducted. ${ }^{[5]}$

- Clinical Examination recorded in case taking performa.

- Diagnostic studies -To suspect iron deficiency anemia especially in those cases where blood loss was likely associated with menorrhagia, pregnancy and poor diet.) ${ }^{[6]}$

- Statistical Techniques \& Data Analysis: Frequency tables, bar charts, pie charts were used as statistical analysis were calculated with the help of Win Pipi application

- Ethical Issue: Ethical clearance was obtained from the College Ethical Committee.

\section{RESULT}

- Out of total 76 cases, 43 were anaemic and 33 were non- 
anaemic.(FIGURE 1)

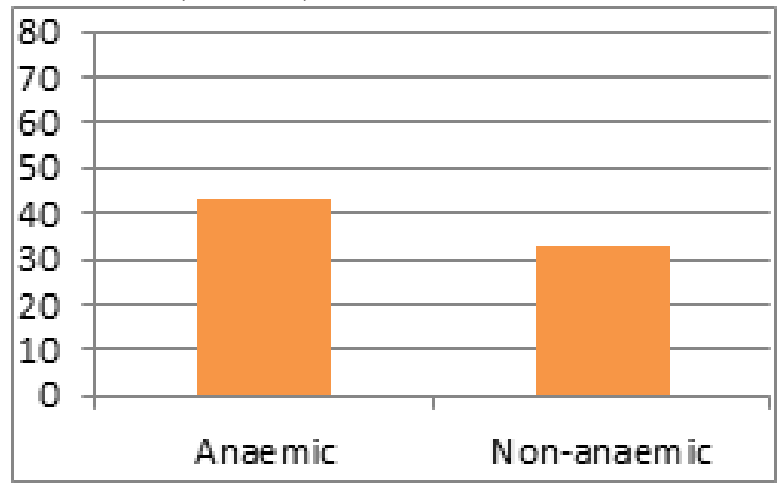

Figure 1: Anaemic And Non-anaemic Cases

- With the help of Haemogram all the anaemic cases were distributed as Mild, Moderate and Severe. The results are as shown in FIGURE 2 .

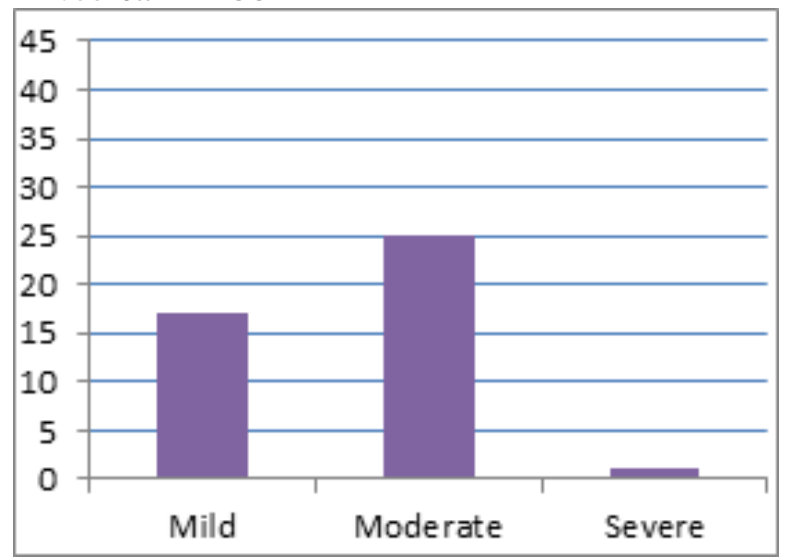

Figure 2: Mild, Moderate \& Severe Cases Of Anaemia

- A summary of baseline observations are provided in TABLE 1.The following observations were made out of the study data with respect to the following variables.

Table 1 Baseline Distribution Of Anaemic And Non Anaemic Girls

\begin{tabular}{|c|c|c|c|c|c|}
\hline Variables & Anemic & $\%$ & Non anemic & $\%$ & Tests \\
\hline \multicolumn{6}{|c|}{ Knowledge } \\
\hline Average & 31 & 72.09 & 20 & 60.60 & \multirow{3}{*}{$\begin{array}{l}\text { Fisher's } p \\
=0.0886\end{array}$} \\
\hline Good & 07 & 16.27 & 12 & 36.36 & \\
\hline Poor & 05 & 11.62 & 01 & 3.03 & \\
\hline \multicolumn{6}{|l|}{ Diet } \\
\hline Vegetarian & 23 & 53.48 & 11 & 33.33 & \multirow{3}{*}{$\begin{array}{l}\text { Fisher's } p \\
=0.1972\end{array}$} \\
\hline Mixed & 17 & 39.53 & 18 & 54.54 & \\
\hline $\begin{array}{l}\text { Non } \\
\text { vegetarian }\end{array}$ & 03 & 6.97 & 04 & 12.12 & \\
\hline \multicolumn{6}{|l|}{ Appetite } \\
\hline Good & 35 & 81.39 & 23 & 69.69 & \multirow{2}{*}{$\begin{array}{l}\text { chi-square } \\
p-234449\end{array}$} \\
\hline Decreased & 08 & 18.60 & 10 & 30.30 & \\
\hline \multicolumn{6}{|c|}{ Menstruation } \\
\hline Heavy & 24 & 55.81 & 06 & 18.18 & \multirow{3}{*}{$\begin{array}{l}\text { Fisher's } p \\
=0.0026\end{array}$} \\
\hline Moderate & 15 & 34.88 & 22 & 66.66 & \\
\hline Scanty & 04 & 9.30 & 05 & 15.15 & \\
\hline
\end{tabular}

- Out of 76 participants, 43 were anaemic. Though the result is not significant for knowledge about anaemia as Fisher's $p=$ 0.0886 , it is observed that $72.09 \%$ of female participants had average knowledge about anaemia, $16.27 \%$ had good knowledge and $11.62 \%$ had poor knowledge.

- In non anaemic participants it was found that $60.60 \%$ of female participants had average knowledge about anaemia, $36.36 \%$ had good knowledge and $3.03 \%$ had poor knowledge about anemia. vegetarian diet, $39.53 \%$ had mixed diet and only $6.97 \%$ had non vegetarian diet. In 33 non anaemic participants $54.54 \%$ had mixed diet, $33.33 \%$ had vegetarian and $12.12 \%$ had non vegetarian diet. The Fisher's $p=0.1972$, therefore the test is not significant.

- $81.39 \%$ girls who had good appetite were found to be anaemic and $18.60 \%$ girls who had decreased appetite were also anaemic. In opposite to that $69.69 \%$ girls with good appetite were non anaemic and $30.30 \%$ of girls who has decreased appetite were non anaemic participants. Hence the results are not significant for this case as chisquare $p$ - 234449 .

- Out of 43 anaemic participants 24(55.81\%) had heavy menstrual flow, 15(34.88\%) had moderate flow and $4(9.30 \%)$ had scanty flow during menstrual cycle. Among non anaemic participants, the results were significant, 33 non anaemic participants $22(66.66 \%)$ had moderate flow, $6(18.18 \%)$ had heavy flow and $5(15.15 \%)$ had scanty flow during menstrual cycle. Fisher's $p-0.0026$ hence the test was found significant for this condition.

- Out of 76 participants the percentage of anaemic girls who had pallor were $27.90 \%$ and remaning $72.09 \%$ did not have pallor. Also in 33 non anaemic participants the 100\% girls did not have pallor. This is given as per the TABLE 2 .

Table - 2 Percentage Of Pallor In Anaemic And Non Anaemic Girls

\begin{tabular}{|c|c|c|c|c|}
\hline Pallor & Anemic & $\%$ & Non anemic & $\%$ \\
\hline Absent & 31 & $72.09 \%$ & 33 & $100 \%$ \\
\hline Present & 12 & $27.90 \%$ & 00 & $00 \%$ \\
\hline
\end{tabular}
DISCUSSION

There is significant prevalence of iron deficiency anaemia in girls between the age group of 18-23 years adolescence and adults ${ }^{[7]}$. Results showed that sign and symptoms wise more than half of the subjects reported fatigue, lethargy. In the study it was seen that out of 76 subjects, 43 were anaemic. A single cause was not responsible for causing anaemia. In some cases it was seen that females were having multiple causes. Not a single subject had excellent knowledge of anaemia. Lacking of knowledge and no attempts to create awareness for the same is the major drawback for causing such a scenario.

\section{CONCLUSION}

Anaemia continues to be a common health problem among adolescence girls and reproductive age women. Most of the female participants had poor knowledge about anaemia - its prevention and management. The current study was to estimate the prevalence of anaemia in adolescence girls and adult women ${ }^{[8]}$. And the findings showed that there is high prevalence of anaemia in adolescence girls and adult women. Excessive blood loss during menses/menorrhagia, traditional eating habits, fear of gaining weight and examination anxiety and irregular eating habits are major causes for anaemia. There is a need to improve health care services, and to improve the knowledge of adolescence girls and adult women about anemia and its prevention. Public should be educated regarding iron rich food and it should be made available for females. The family members must care for females of the family.

Early detection of anaemia is important, so that mild and moderate anemia can be promptly treated and prevented from developing severe anaemia which can adversely affect health.

\section{REFERENCES}

1. Park, K. (2011). Park's textbook of preventive and social medicine. Jabalpur. Banarasidas Bhanot,

2. Konar,H. (2018).DCDutta's Textbook of obstetrics.JP Medical Ltd.

3. Chatterjee's, C.C.Text book of Human Physiology.

4. Murray A, (1998). Women's Health Care Handbook. (First Indian Edition), Jaypee Brothers Medical Publishers (pvt) Ltd.

5. Miller, J. L. (2013). Iron deficiency anemia: a common and curable disease. Cold Spring Harbor perspectives in medicine, 3(7), a011866. 
6. Johnson-Wimbley,T.D., \& Graham, D.Y.(2011).Diagnosis and management of iron deficiency anemia in the 21 st century. Therapeutic advances in Gastroenterology, 4(3), 177-184.

7. Al-Alimi, A. A., Bashanfer, S., \& Morish, M. A. (2018). Prevalence of iron deficiency anemia among university students in Hodeida province, Yemen. Anemia,2018.

8. Chaudhary, S. M., \& Dhage, V. R. (2008). A study of anemia among adolescent females in the urban area of Nagpur. Indian journal of community medicine: official publication of Indian Association of Preventive \& Social Medicine, 33(4), 243. 